\title{
Signaling mechanisms coupled to tyrosines in the granulocyte colony-stimulating factor receptor orchestrate G-CSF-induced expansion of myeloid progenitor cells
}

\author{
Mirjam H. A. Hermans, Gert-Jan van de Geijn, Claudia Antonissen, Judith Gits, Daphne van Leeuwen, Alister C. Ward, and Ivo P. Touw
}

Granulocyte colony-stimulating factor (G-CSF) is the major regulator of neutrophil production. Studies in cell lines have established that conserved tyrosines Tyr704, Tyr729, Tyr744, Tyr764 within the cytoplasmic domain of G-CSF receptor (G-CSF-R) contribute significantly to GCSF-induced proliferation, differentiation, and cell survival. However, it is unclear whether these tyrosines are equally important under more physiologic conditions. Here, we investigated how individual G-CSF-R tyrosines affect G-CSF responses of primary myeloid progenitors. We generated G-CSF-R-deficient mice and transduced their bone marrow cells with tyrosine "null" mutant $(\mathrm{m} 0)$, single tyrosine "add-back" mutants, or wild-type (WT) receptors. G-CSF-induced responses were determined in primary colony assays, serial replatings, and suspension cultures. We show that removal of all tyrosines had no major influence on primary colony growth. However, adding back Tyr764 strongly enhanced proliferative responses, which was reverted by inhibition of ERK activity. Tyr729, which we found to be associated with the suppressor of cytokine signaling, SOCS3, had a negative effect on colony formation. After repetitive replatings, the clonogenic capacities of cells expressing $\mathrm{mo}$ gradually dropped compared with WT. The presence of Tyr729, but also Tyr704 and Tyr744, both involved in activation of signal transducer and activator of transcription 3 (STAT3), further reduced replating efficiencies. Conversely, Tyr764 greatly elevated the clonogenic abilities of myeloid progenitors, resulting in a more than $10^{4}$-fold increase of colonyforming cells over $\mathrm{m} 0$ after the fifth replating. These findings suggest that tyrosines in the cytoplasmic domain of G-CSF-R, although dispensable for G-CSF-induced colony growth, recruit signaling mechanisms that regulate the maintenance and outgrowth of myeloid progenitor cells. (Blood. 2003;101:2584-2590)

๑) 2003 by The American Society of Hematology

\section{Introduction}

Granulocyte colony-stimulating factor (G-CSF) supports the proliferation, survival, and differentiation of neutrophilic progenitor cells. ${ }^{1-4}$ G-CSF-deficient mice manifest a selective neutropenia, with blood neutrophil levels at $30 \%$ of those in wild-type (WT) mice. Blood neutrophil levels in mice lacking G-CSF receptors $\left(\mathrm{gcsfr}^{-1-}\right)$ are also severely reduced, that is, approximately $15 \%$ of WT littermates. ${ }^{5}$ In addition, the numbers of myeloid progenitor cells in the bone marrow of gcsfr $^{-/-}$mice are significantly decreased. ${ }^{5}$ These observations have established that the G-CSF receptor (G-CSF-R) provides nonredundant signals for maintaining steady-state neutrophil levels. , $^{5,6}$

The G-CSF-R belongs to the cytokine receptor superfamily and possesses a single transmembrane region. ${ }^{1}$ Signaling molecules downstream of the G-CSF-R include Jak1, Jak2, and Tyk2; the signal transducer and activator of transcription (STAT) proteins, STAT1, STAT3, and STAT5 ${ }^{7-13}$; the Src kinases p5 $^{\text {Lyn }}$ and p56/ $59^{\text {Hck14-16; }}$ components of the $\mathrm{p} 21^{\text {Ras }} /$ Raf/mitogen-activated protein kinase (MAPK) pathway ${ }^{17-19}$; and the $\mathrm{SH} 2$ domain-containing protein tyrosine phosphatases SHP-1 and SHP-2. ${ }^{19-21}$ The cytoplasmic domain of human G-CSF-R contains 4 conserved tyrosine residues, at positions 704, 729, 744, and 764 (equivalent to 703, 728,743 , and 763 in mouse G-CSF-R). Three of these tyrosines are located in the carboxy-terminal region implicated in the control of differentiation. 22,23 On receptor activation, these tyrosines are

From the Institute of Hematology, Erasmus University of Rotterdam, the Netherlands; and Deakin University, Burwood, Victoria, Australia.

Submitted July 11, 2002; accepted November 14, 2002. Prepublished online as Blood First Edition Paper, December 5, 2002; DOI 10.1182/blood-2002-07-2062.

Supported by grants from the Netherlands Organization for Scientific Research and the Dutch Cancer Society. phosphorylated and become docking sites for multiple $\mathrm{SH} 2$ containing signaling proteins, for example, STAT3 (Tyr704 and Tyr744), Shc (Tyr764), and Grb2 (Tyr764). ${ }^{21,24,25}$

We previously constructed a series of tyrosine (Tyr) to phenylalanine (Phe) substitution mutants of the G-CSF-R and expressed these in 32D cells to study their involvement in G-CSF signaling. ${ }^{25-27}$ These studies demonstrated that G-CSF-R substitution mutants lacking just 1 of the 4 tyrosines were still fully capable of transmitting differentiation signals in 32D cells. ${ }^{24}$ Strikingly, cells expressing mutant Tyr764Phe showed significantly accelerated differentiation with a concomitant reduction in proliferation, suggesting that Tyr764 plays an essential role in controlling the balance between proliferation and differentiation. Recently, similar observations have been made in primary bone marrow cells transduced with chimeric epidermal growth factor receptor (EGFR)/ G-CSF-R Tyr764Phe. ${ }^{28}$ G-CSF-R lacking all tyrosines (m0) fails to elicit proliferation and differentiation in 32D cells, although survival signals are still transduced. ${ }^{25}$ The presence of Tyr704 or Tyr744, which serve as major docking sites for STAT3, restored G-CSF-induced proliferation and differentiation to a significant extent. ${ }^{13,25}$ Introduction of Tyr764, involved in $\mathrm{p} 21^{\text {Ras }}$ activation and signaling via ERK and p38MAPK pathways, ${ }^{19,24,25,29}$ generated strong proliferative signals resulting in exponential growth without neutrophilic differentiation. A specific function and

Reprints: Ivo Touw, Institute of Hematology, Erasmus University Rotterdam, PO Box 1738, 3000 DR Rotterdam, the Netherlands; e-mail: touw@hema.fgg.eur.nl.

The publication costs of this article were defrayed in part by page charge payment. Therefore, and solely to indicate this fact, this article is hereby marked "advertisement" in accordance with 18 U.S.C. section 1734

(C) 2003 by The American Society of Hematology 
signaling mechanism linked to Tyr729 did not emerge from these studies.

The mechanisms by which G-CSF signaling is negatively regulated have not been elucidated. In contrast to, for example, the erythropoietin (EPO) receptor or granulocyte-macrophage colonystimulating factor (GM-CSF)/interleukin 3 (IL-3)/IL-5 receptor common $\beta$ chain, G-CSF-R tyrosines do not serve as docking sites for the protein tyrosine phosphatase SHP-1, although negative effects of SHP-1 on G-CSF signaling have been reported. ${ }^{20,30,31}$ Because STAT3 and STAT5 are prominently activated by G-CSF, it is conceivable that suppressor of cytokine signaling (SOCS) proteins, which are under the direct transcriptional control of STATs, are involved in down-modulation of G-CSF responses. ${ }^{32-34}$ The SH-2 domain of SOCS1 has a high affinity for JAK kinases and interferes directly with JAK activity. ${ }^{35}$ On the other hand, other SOCS proteins, such as SOCS3, are recruited to phosphotyrosines in activated receptors and exert their negative activity either by blocking positively acting signaling substrates docking to the same receptor tyrosine, by inhibiting the activity of receptor-associated kinases, or by proteosomal targeting of signaling molecules. ${ }^{32-34}$

Although myeloid cell lines have provided useful models for studying G-CSF signaling, these cells are transformed and immortalized and therefore do not fully recapitulate the physiologic features of normal myeloid progenitor cells. In the present study, we have used retroviral transduction of G-CSF-R mutants into bone marrow cells of G-CSF-R-deficient mice to investigate how signals emanating from the cytoplasmic tyrosine residues in the G-CSF-R contribute to the clonogenic abilities of primary murine myeloid progenitor cells. We show that tyrosines are dispensable for G-CSF-induced colony formation per se, but individually contribute significantly to both G-CSF-induced colony growth and the maintenance of clonogenicity after sequential replatings. Prominent negative regulatory effects on colony growth were projected by Tyr729, which we found to be associated with recruitment of SOCS3. Conversely, Tyr764 greatly enhanced proliferative signals through activation of the Erk kinases.

\section{Materials and methods}

\section{Cells and culture}

Embryonic stem (ES) cells (ES-E14), a gift from M. Hooper (Edinburgh, United Kingdom), were cultured as described.$^{36}$ Briefly, cells were grown in culture medium consisting of Dulbecco modified Eagle medium (DMEM, Gibco BRL, Breda, The Netherlands), 50\% Buffalo rat liver-conditioned medium, $10 \%$ fetal calf serum (FCS, ES qualified; Gibco-BRL) supplemented with $1 \%$ nonessential amino acids (Gibco BRL), $0.1 \mathrm{mM}$ 2-mercaptoethanol (Sigma Chemical, St Louis, MO), $100 \mathrm{U} / \mathrm{mL}$ penicillin, 100 $\mu \mathrm{g} / \mathrm{mL}$ streptomycin (Gibco BRL), and $1000 \mathrm{U} / \mathrm{mL}$ leukemia inhibitory factor (LIF; Gibco BRL) in dishes coated with $0.1 \%$ gelatin (G-1890; Sigma). The cells were passaged every 2 to 3 days.

\section{Targeting construct and probe}

The targeting strategy used to inactivate the gcsfr gene is shown in Figure 1. Isolation, cloning, and sequencing of gDNA were done according to standard procedures. ${ }^{37} \mathrm{gDNA}$ was isolated from a mouse 129SV/Cosmid library (Cosmid SC1-6 SuperCos 1, Stratagene Cloning Systems, La Jolla, CA) as described.$^{38}$ A region of $10 \mathrm{~kb}$ including exon 7 to 17 of the $g c s f r$ gene was replaced by a Neo gene driven by the PGK promoter. To construct the targeting vector, a 2.9-kb Sau3AI-PstI fragment containing exon 5 and 6 and a $4.5-\mathrm{kb} X b a \mathrm{I}$ fragment, 3-prime of the gcsfr gene, including the noncoding region of exon 17 , were cloned into pBluescript yielding pEUR11 and pEUR5, respectively. pEUR5 was opened by SpeI, and
A
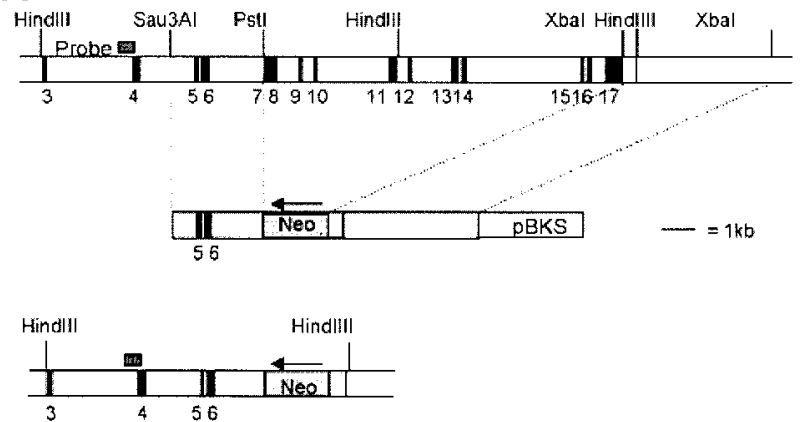

B
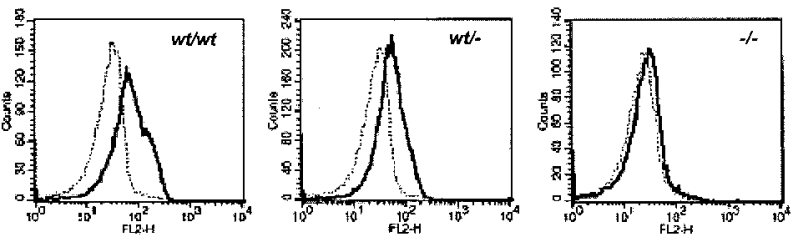

Figure 1. Targeting strategy to inactivate gcsfr gene. (A) Targeting strategy to delete exons 7 to 16 of the gcsfr gene in ES cells. The position of the probe used to screen recombinant colonies is shown. Southern analysis of HindllI digests of gDNA detected a $9.6-\mathrm{kb}$ band from the WT allele and a $7-\mathrm{kb}$ band from the targeted allele (not shown). pBKS indicates pBluescript KS (Stratagene, La Jolla, CA). (B) Specific binding of G-CSF to bone marrow cells from $\mathrm{gcsfr}^{+/+}, \mathrm{gcsfr}^{+/-}$, and $\mathrm{gcsf}^{-1-}$ mice analyzed by flow cytometry. Cells were incubated with biotinylated G-CSF in the absence (solid line) or presence (dotted line) of a 100-fold molar excess of nonlabeled G-CSF followed by incubation with PE-conjugated streptavidin.

PGK-Neo was inserted in reverse orientation, yielding pEUR17. pEUR17 was opened by NotI, blunted, and subsequently cut by XhoI. The resulting 6.5-kb NotI-XhoI fragment containing the 4.5-kb XbaI fragment and the $P G K$-Neo gene was ligated into pEUR11 after ApaI opening, blunting, and subsequent XhoI digestion, resulting in pEUR18. A unique NotI site in the vector backbone was used for linearization prior to transfection. A $0.6-\mathrm{kb}$ Sau3A fragment 5-prime of exon 4 (probe A) was used to screen for homologous recombination, yielding a $9.6-\mathrm{kb}$ band in germ line configuration, and a 7-kb band after homologous recombination.

\section{Disruption of the gcsfr gene by homologous recombination}

ES-E14 cells $\left(10^{7}\right)$ were transfected with $25 \mu \mathrm{g}$ linearized pEUR18 by electroporation using a Progenetor II, PG200 Hoefer Gene pulser set at 350 $\mathrm{V} / \mathrm{cm}, 1200 \mu \mathrm{F}, 10 \mathrm{msec}$. The next day, cells were transferred to culture medium containing $200 \mu \mathrm{g} / \mathrm{mL}$ Gly418 (Gibco BRL), with Gly418resistant colonies picked on day 8 or 9 after electroporation. gDNA of these colonies was digested with HindIII, transferred to nylon membranes, and hybridized to probe A and a neomycin probe. Correctly targeted clones were subjected to cytogenetic analysis and clones with a normal karyotype were used for blastocyst injections.

\section{Generation of gcsfr knock-out mice}

Two ES cell clones were injected into blastocysts of C57BL/6 mice. The resulting male chimeras were mated to FVB females to generate csffr $^{+/-}$ F1 mice. Heterozygous $\mathrm{gcsfr}^{+/-}$mice were intercrossed to obtain $\mathrm{gcsfr}^{-/-}$ mice. DNA was isolated from tail segments and analyzed by polymerase chain reaction (PCR) using primers for exon 17 (5'-GTATATCCCTGTGTTCAGGAAACC and 5'-GGCAGGGTCTTCAAGATACAAGG) and primers for the neo gene (5'-TACTCGGATGGAAGCCGGTC and 5'-AGTCGATGAATCCAGAAAAG).

\section{Flow cytometric analysis of G-CSF-R expression}

Expression levels of G-CSF-R on neutrophilic cells were measured by flow cytometry. To this end, G-CSF was biotinylated using D-biotinoyl- $\epsilon-$ aminocaproic acid-N-hydroxysuccinimide ester (Biotin-7-NHS; Boehringer, Mannheim, Germany). Free biotin was removed by gel filtration on 
Sephadex G-25. Bone marrow cells $\left(10^{6}\right)$ were incubated in 96-well plates for 60 minutes at room temperature in $25 \mu \mathrm{L}$ PBA (phosphate-buffered saline with $1 \%$ bovine serum albumin (BSA) and $0.1 \% \mathrm{NaN}_{3}$ ) and 0.2 $\mu \mathrm{g} / \mathrm{mL}$ biotinylated G-CSF, either in the absence or the presence of a 100 -fold molar excess of nonbiotinylated G-CSF. Subsequently, cells were incubated for 30 minutes at $4^{\circ} \mathrm{C}$ with phycoerythrin-conjugated streptavidin (SA-PE; Caltag Laboratories, Burlingame, CA). To determine G-CSF-R expression on transduced bone marrow cells, cells were labeled for 30 minutes at $4^{\circ} \mathrm{C}$ with biotinylated antihuman G-CSF-R antibody (LMM741; Pharmingen, San Diego, CA) and subsequently with SA-PE. Cells were subjected to flow cytometric analysis on a FACScan (Becton Dickinson, Sunnyvale, CA).

\section{Construction of G-CSF-R retroviral vectors and virus production}

Vectors containing cDNA encoding human G-CSF-R WT and tyrosine substitution mutants have been described previously. ${ }^{13}$ Inserts were recloned into the retroviral vector $\mathrm{pBabe}$, containing a puromycin-resistance gene. Correct insertion was verified by nucleotide sequencing. Phoenix E virus producer cells (a gift from G. Nolan, Stanford, CA) were transfected with these constructs using Promega Profection Mammalian Transfection Systems (Promega, Madison, WI). Supernatants containing high-titer, helper-free recombinant viruses were harvested after culturing approximately $80 \%$ confluent producer cells for 16 to 20 hours in DMEM medium (with 5\% FCS and penicillin/streptomycin) and passed through a $45-\mu \mathrm{m}$ filter before use.

\section{Retroviral infection of hematopoietic progenitor cells}

Bone marrow cells were harvested from the femurs and tibiae of 8- to 12-week-old G-CSF-R-deficient mice as described. ${ }^{38}$ After depletion of adherent cells, the remaining cells were fractionated on a Percoll density gradient (Amersham Pharmacia Biotech, Uppsala, Sweden) as described. ${ }^{39}$ Cells were washed twice in Hanks balanced salt solution (HBSS)/5\% FCS $/ 0.5 \%$ BSA, and prestimulated for 2 days in Cell Gro (Boehringer Ingelheim Bioproducts Partnership, Heidelberg, Germany) supplemented with a cytokine cocktail containing murine IL-3 $(10 \mathrm{ng} / \mathrm{mL})$, human FLT3 ligand, human thrombopoietin (hTPO), murine stem cell factor (mSCF), and GM-CSF (all $100 \mathrm{ng} / \mathrm{mL}$ ) at a final density of $5 \times 10^{5}$ cells $/ \mathrm{mL}$. Cells where then transferred to 35-mm culture dishes (Becton Dickinson, Lincoln Park, NJ) coated with $12 \mu \mathrm{g} / \mathrm{mL}$ recombinant fibronectin fragment CH-296 (Takara Shuzo, Otsu, Japan) and preincubated with the appropriate virus supernatant for 30 minutes at $37^{\circ} \mathrm{C}$. Subsequently, bone marrow cells $\left(10^{6}\right.$ cells $/ \mathrm{mL}$ ) were mixed with fresh virus supernatant in a 1:1 ratio, supplemented with a fresh cytokine cocktail, and cultured overnight at $37^{\circ} \mathrm{C}$ and $5 \% \mathrm{CO}_{2}$. Virus supernatant and cytokine cocktail were once again refreshed the next day and the cells cultured for an additional 24 hours.

\section{Progenitor cell assays and suspension culture}

Bone marrow cells were plated in triplicate at densities of $1 \times 10^{5} / \mathrm{mL}$ in methyl cellulose medium supplemented with $30 \%$ FBS, $1 \%$ BSA, $0.1 \mathrm{mM}$ 2-mercaptoethanol, $2 \mathrm{mM}$ L-glutamine, and G-CSF (100 ng/mL). To calculate infection efficiencies for the different receptor mutants, cells were also plated in GM-CSF $(20 \mathrm{U} / \mathrm{mL})$ containing colony assays, with or without $2.5 \mu \mathrm{g} / \mathrm{mL}$ puromycin (Sigma, Zwijndrecht, The Netherlands). Colonies ( 30 cells or more) were counted on day 7 of culture. For cytologic analysis and replating experiments, colony cells were mass harvested and washed twice in HBSS. Suspension cultures were performed in RPMI (Gibco BRL) supplemented with 10\% FCS and $100 \mathrm{ng} / \mathrm{mL}$ G-CSF. Every 3 to 4 days, culture medium was renewed and cells were counted on a Casy R-1 cell counter (Scharfe System, Reutlinger, Germany). Cell densities were kept between $0.3 \times 10^{6}$ and $1 \times 10^{6} / \mathrm{mL}$. For inhibitor studies, cells were grown as described, in the presence of either $10 \mu \mathrm{M}$ SB203580 or U0126 (Calbiochem, San Diego, CA) dissolved in dimethyl sulfoxide (DMSO) or $0.1 \%$ ( vol/vol) DMSO as a solvent control. Viable cells were counted daily and every second day cells were spun down and resuspended in fresh media with fresh inhibitor. Cell densities of proliferating cells were kept between 0.5 and $1.5 \times 10^{6}$ cells $/ \mathrm{mL}$. Cell viability was assessed by flow cytometric analysis (FACScan, Becton Dickinson, Sunnyvale, CA) using 7-amino actinomycin D (7-AAD; Molecular Probes, Eugene, OR),

\section{Reporter assay for SOCS3 effects on G-CSF-R activity}

To determine the effects of SOCS3 on the activity of G-CSF-R and mutants, we used a STAT5 luciferase assay essentially as described previously. ${ }^{40}$ In brief, HEK 293 cells, seeded in 24 -well dishes at $0.2 \times 10^{6}$ cells/well in $1 \mathrm{~mL}$ DMEM/10\% FCS, were cultured overnight and transfected by means of standard $\mathrm{Ca}-\mathrm{PO}_{4}$ precipitation with a mixture of the following plasmids: pME18S-STAT5 for expression of STAT5, a STAT5 luciferase reporter plasmid consisting of 5 repeats of the $\beta$-casein sequence upstream of a SV40 promoter in the pGL-3-promotor vector (Promega), a $\beta$-galactosidase expression plasmid pRSVLacZ, derived from $\mathrm{pCH} 110,{ }^{41} \mathrm{pcDNA3}-$ SOCS $3,{ }^{42}$ or empty pcDNA3 (Invitrogen, Breda, The Netherlands) and pBabe with the different G-CSF-R mutants. A volume of $100 \mu \mathrm{L}$ precipitate with a total of $2 \mu \mathrm{g}$ DNA (400 ng DNA for each construct) was added to

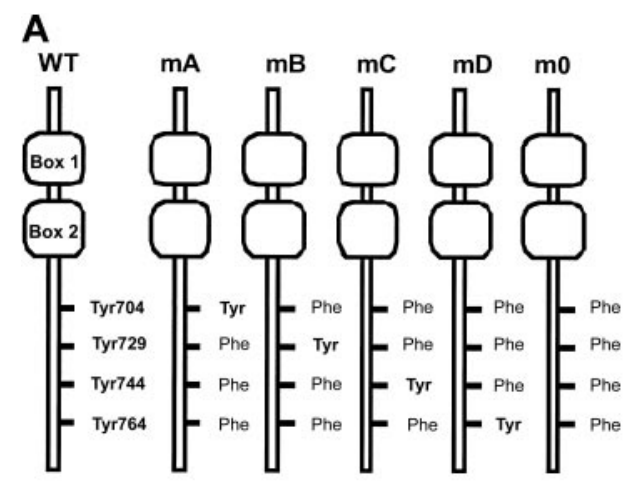

B
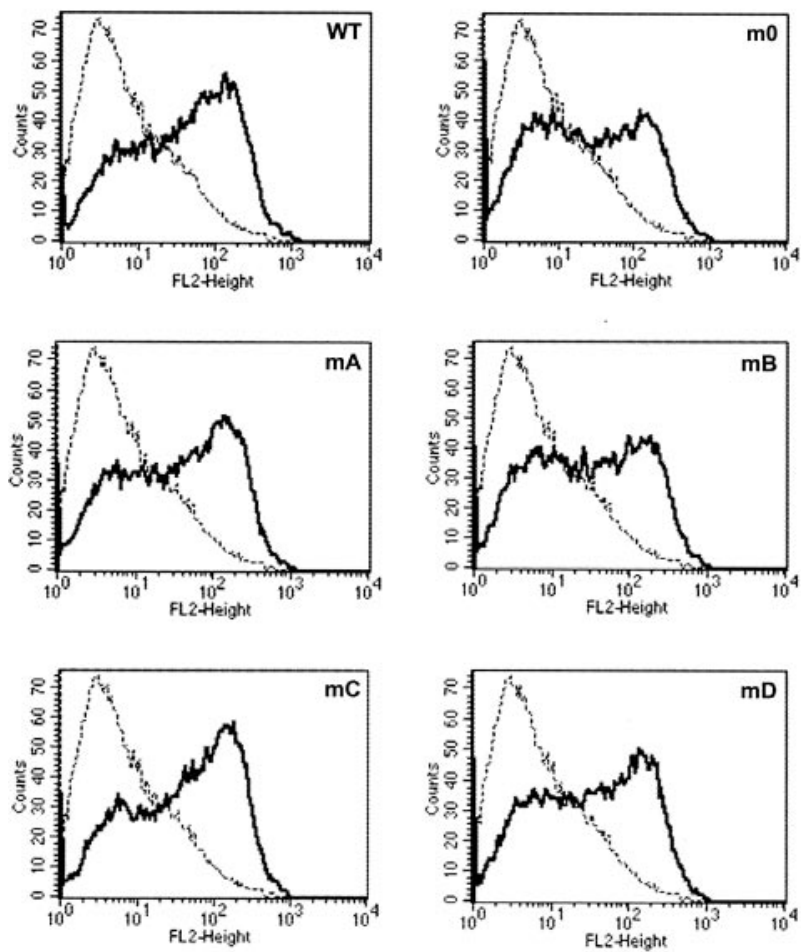

Figure 2. Expression of G-CSF-R mutants. (A) Schematic representation of cytoplasmic domains of human G-CSF-R wild-type and tyrosine substitution mutants showing positioning of conserved tyrosines relative to membrane proximal Box1 and Box2. (B) Flow cytometric analysis of G-CSF-R expression on gcsfr $^{-1}$ bone marrow cells retrovirally transduced with G-CSF-R WT and tyrosine mutants shown in panel A. Bold histograms indicate cells stained with biotinylated G-CSF-R antibodies and SA-PE; dotted histograms, cells stained with SA-PE only. 

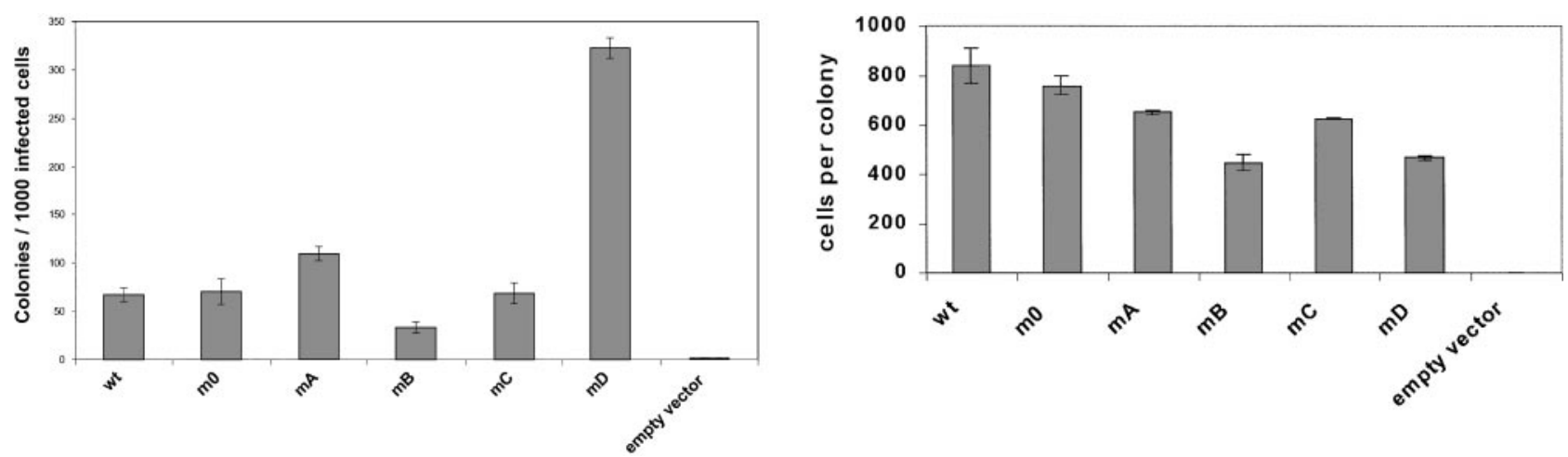

Figure 3. Primary colony formation by gcsfr $^{-/}$bone marrow progenitors transduced with different G-CSF-R constructs. Colonies were grown in the presence of 100 $\mathrm{ng} / \mathrm{mL}$ G-CSF. Left panel shows mean colony numbers \pm SD per 1000 infected bone marrow cells from triplicate colony dishes; data are representative of 4 independent experiments. Colony numbers were normalized to the numbers of infected cells based on puromycin resistance of CFU-GMs (responsive to GM-CSF) to correct for differences due to variations in transduction efficiencies. Right panel shows mean numbers of cells per colony \pm SD from triplicate dishes.

each well. For SOCS3, $12.5 \mathrm{ng}$ SOCS3 supplemented with $387.5 \mathrm{ng}$ pcDNA3 (empty vector) was added. On day 4 , the cells were stimulated for 6 hours with $100 \mathrm{ng} / \mathrm{mL}$ G-CSF and subsequently lysed in $100 \mu \mathrm{L}$ lysis buffer $(25 \mathrm{mM}$ Tris [tris(hydroxymethyl)aminomethane] phosphate, $\mathrm{pH}$ 7.8, $15 \%$ glycerol, $1 \%$ Triton X-100, $1 \mathrm{mM}$ dithiothreitol [DTT], $8 \mathrm{mM}$ $\left.\mathrm{MgCl}_{2}\right)$. To measure luciferase activity, cell lysates $(25 \mu \mathrm{L})$ were transferred to 96-well flat bottom plates (Costar, Corning, Corning, NY) and $25 \mu \mathrm{L}$ of a $16 \mathrm{mg} / \mathrm{mL}$ luciferase substrate-containing buffer (Steady-Glo luciferase assay System; Promega) was added to each well. Emitted light was measured in a TopCount luminometer (Packard, Meriden, CT). To correct luciferase activity levels for variations in transfection efficiencies, $25 \mu \mathrm{L}$ cell lysate was incubated in parallel with $75 \mu \mathrm{L} \beta$-galactosidase substrate buffer $\left(100 \mathrm{mM} \mathrm{Na}-\mathrm{PO}_{4}\right.$ buffer, $\mathrm{pH} 7.8,10 \mathrm{mM} \mathrm{KCl}, 1 \mathrm{mM}$ $\mathrm{MgSO}_{4}, 2.7 \mathrm{mM}$ DTT) and $0.56 \mathrm{mg} / \mathrm{mL}$ O-nitrophenyl $\beta$-D-galactopyranoside (oNPG; Sigma) for 15 minutes at $37^{\circ} \mathrm{C}$. Absorption was measured in a microplate reader (Biorad 450; Veenendaal, The Netherlands) at $450 \mathrm{~nm}$. All experiments were performed in duplicate.

\section{Results}

\section{Generation of gcsfr-deficient mice}

To inactivate the murine gcsfr gene, we constructed a targeting vector in which the genomic sequence spanning exon 7 to 17 was replaced by a pgk-Neo selection cassette (Figure 1A). Two independently isolated ES cell clones were injected into blastocysts and the resulting chimeras were crossed with FVB mice. Germ line transmission of the knock-out allele was achieved for both clones. Flow cytometric analysis of bone marrow neutrophils using

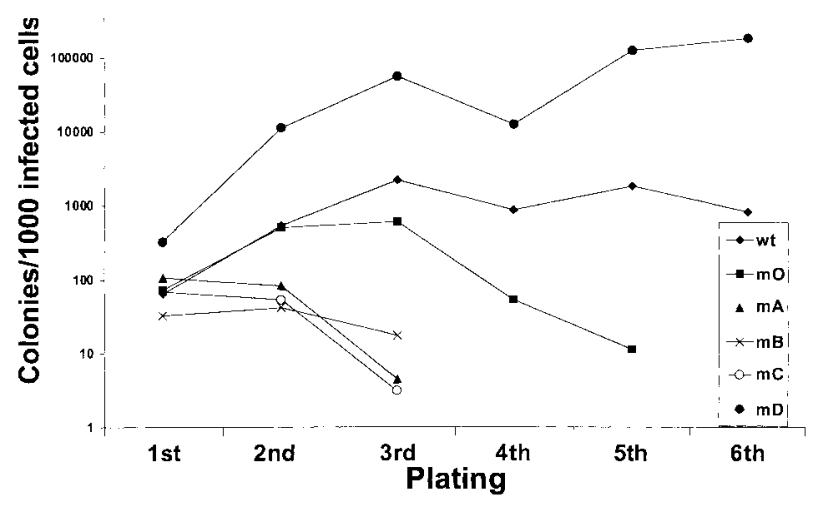

Figure 4. Serial replatings of progenitor cells from $\mathrm{gcsfr}^{-1}$ bone marrow transduced with G-CSF-R expression constructs. biotinylated G-CSF confirmed the absence of G-CSF-R in gcsfr $^{-/-}$ mice and a $50 \%$ reduced expression in $g_{c s f r^{+/-}}$mice (Figure $1 \mathrm{~B}$ ). In agreement with a previously reported gcsfr knock-out line, ${ }^{5}$ peripheral neutrophil counts in this gcsfr $^{-/-}$strain are $15 \%$ to $20 \%$ of levels found in WT littermates.

\section{Role of receptor tyrosines in G-CSF-induced colony formation}

To study the involvement of receptor tyrosines in G-CSF-Rmediated signaling in primary hematopoietic cells, we introduced single tyrosine add-back mutants, m0, G-CSF-R WT, or Babe control vector (Figure 2), into $g c s f^{-/-}$bone marrow cells and determined G-CSF responses in colony assays. As predicted, no colonies were formed by $g c s f^{-1-}$ cells transduced with Babe vector (Figure 3, left panel). Cells expressing $\mathrm{m} 0$ produced colonies at numbers equivalent to cells transduced with G-CSF-R WT. At first glance, these data would suggest that the receptor tyrosines are fully dispensable for G-CSF-controlled colony growth. However, experiments with the add-back mutants unveiled a more subtle scenario. Expression of $\mathrm{mA}$ (Tyr704) slightly increased colony formation, whereas colony numbers obtained with $\mathrm{mC}$ (Tyr744) were similar to $\mathrm{m} 0$. Colony formation induced by $\mathrm{mB}$ (Tyr729) was reduced by approximately 50\%, indicating that Tyr729 has a negative influence on G-CSF-induced colony growth. The presence of Tyr764 $(\mathrm{mD})$ resulted in approximately 6-fold increase in cloning efficiency. Assessment of the mean number of cells per colony did not show a correlation between colony number and size, except for $\mathrm{mB}$ (Figure 3, right panel). The latter observation suggests that negative signals emanating from Tyr729 affect both clonogenicity as well as proliferative potential of the transduced progenitor cells. Morphologic analysis revealed no differences in the composition of colonies induced by the various receptor forms, suggesting that the receptor tyrosines are dispensable for G-CSFinduced differentiation (data not shown).

\section{G-CSF-R tyrosines are involved in G-CSF-dependent maintenance of myeloid progenitor cell levels}

We next investigated to what extent G-CSF-R tyrosines contribute to the expansion of the progenitor cells in serial replatings. As shown in Figure 4, progenitor cells transduced with WT G-CSF-R maintained recloning abilities at a relatively constant level up to the sixth replating. In contrast, replating abilities of m0-expressing cells gradually declined after the third replating, suggesting that receptor tyrosines are required for sustained G-CSF-dependent maintenance and expansion of myeloid progenitor cells. The 


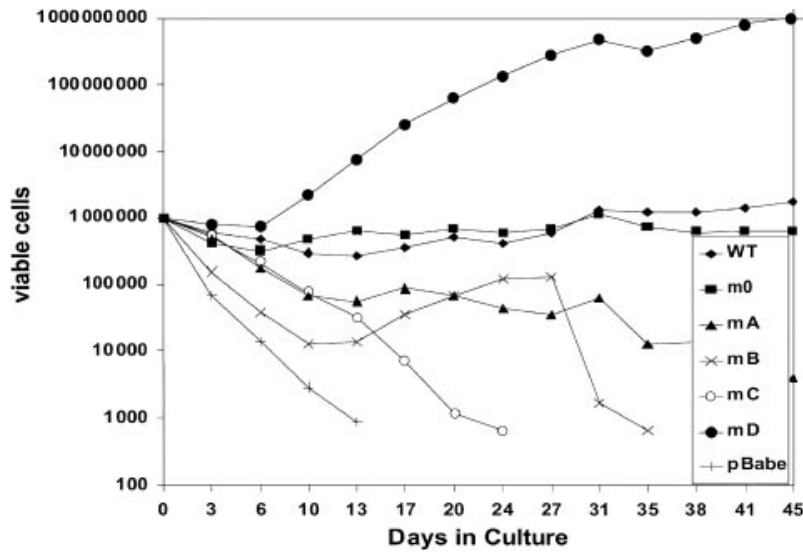

Figure 5. Expansion of gcsfr $^{-/}$bone marrow cells transduced with G-CSF-R expression constructs in suspension culture. Cells were cultured in the presence of $100 \mathrm{ng} / \mathrm{mL}$ G-CSF. Viable cell counts and replenishment of culture media were performed at 3- to 4-day intervals.

presence of Tyr729 (mB), Tyr704 (mA), or Tyr744 (mC) further suppressed the recloning potential of progenitors. In contrast, the presence of Tyr764 (mD) alone greatly enhanced recloning potential, resulting in colony numbers after the fifth replating that were 100-fold higher than WT and 10000-fold higher than m0expressing cells cultured in parallel. The sustained expansion of progenitor cells mediated via Tyr764 also translated into exponential cell proliferation in long-term suspension culture (Figure 5). These expanded cells did not express mainly features of immature blast cells, but rather represented a mixture of myeloid cell types at various stages of differentiation. Notably, the cells remained fully dependent on G-CSF for proliferation (data not shown). Cell numbers were maintained at relatively stable levels in cultures from cells expressing WT and m0 G-CSF-R, whereas cells expressing $\mathrm{mA}, \mathrm{mB}$, or $\mathrm{mC}$ progressively lost proliferative abilities.

\section{Proliferative signals from Tyr764 are mediated via Erk}

Tyr764 is a docking site for connector proteins implicated in p21 Ras/MAPK signaling and has been shown to play a prominent role in the activation of Erk as well as p38. ${ }^{17,24,29}$ We therefore studied the effects of the MEK1 inhibitor U0126, which blocks activation of Erk1 and Erk2, and the p38 inhibitor SB203580 on G-CSF-induced proliferation of bone marrow cells expressing $\mathrm{mD}$ in suspension culture. As shown in Figure 6, addition of U0126 to the cultures inhibited proliferation, whereas the effects of SB203580 were minimal. These findings establish that Erk kinases are the principle mediators of proliferative signaling via Tyr764 of the G-CSF-R.

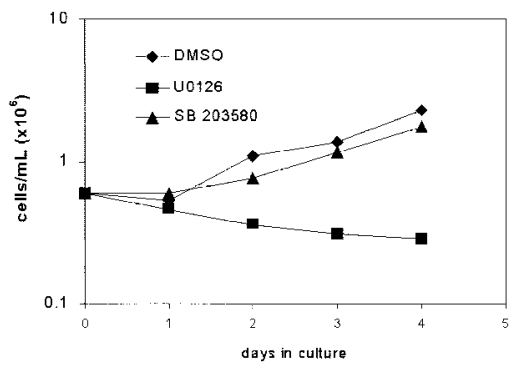

Figure 6. Effects of inhibitors of MEK (U0126) and p38MAPK (SB203580) on proliferation of $\mathrm{mD}$-expressing cells.

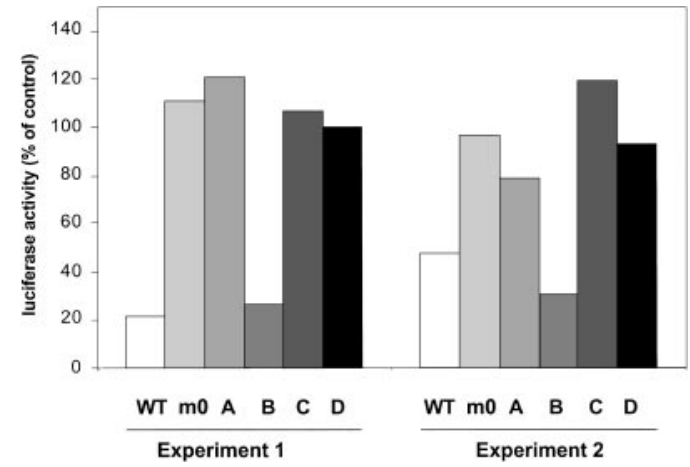

Figure 7. STAT5-luciferase reporter assay showing prominent inhibitory effects of cotransfection of pcDNA-SOCS3 on G-CSF-R WT and mB (Tyr729). Data are expressed as the percentage of activity measured after cotransfection of pcDNA3 empty vector.

\section{SOCS3 inhibits G-CSF responses via Tyr729 of G-CSF-R}

Recently, several studies have demonstrated that SOCS3 mediates its inhibitory activity on a variety of cytokine receptors, for example, leptin receptor and gp130, via binding to receptor tyrosines. ${ }^{42,43}$ Based on structural similarities between G-CSF-R and gp130, we performed a G-CSF-R activity assay based on the onset of STAT5-mediated gene expression, which is activated via the membrane proximal region of G-CSF-R. ${ }^{27}$ Introduction of SOCS3 severely interfered with activity of G-CSF-R WT (Figure 7). In contrast, under similar conditions, activity of $\mathrm{m} 0$ was not affected, confirming that one or more of the receptor tyrosines are involved in SOCS3 recruitment. Experiments with single tyrosine add-back mutants subsequently showed inhibition only with $\mathrm{mB}$, suggesting that Tyr729 is the major binding site for SOCS3. We suggest on the basis of these data that the negative effects generated by Tyr729 on G-CSF-R signaling are mediated by SOCS3.

\section{Discussion}

The aim of this work was to investigate to what extent signals from G-CSF-R tyrosines contribute to the G-CSF-induced responses of primary myeloid progenitor cells. Previous studies in myeloid factor-dependent cell lines have revealed that these tyrosines contribute to G-CSF-dependent proliferation, differentiation, and survival via signaling mechanisms involving the activation of STAT3 and p21 Ras. 17,21,24,25,29,44 Although these models have provided useful information, it has also become clear that major discrepancies in signaling requirements exist between cell lines and primary cells. For instance, STAT3 was shown to induce growth arrest and neutrophilic differentiation in cell lines, whereas a recent study in a transgenic mouse model demonstrated that STAT3 is essential for G-CSF-induced proliferation of primary myeloid progenitors. ${ }^{40,45,46}$ The fact that certain mechanisms underlying growth factor-induced proliferation of primary progenitor cells are bypassed or constitutively activated in cell lines is likely to contribute to such differences.

Some of the findings reported here are consistent with certain observations in cell lines. For instance, Tyr764 confers hyperproliferative responses to G-CSF in both primary progenitor cells and cell lines. ${ }^{25}$ However, $\mathrm{m} 0$, which was unable to transduce proliferation signals in 32D cells, fully supported G-CSF-induced colony formation of primary progenitors at plating efficiencies comparable to G-CSF-R WT. Thus, coupling of signaling mechanisms to 
G-CSF-R tyrosines in primary myeloid progenitor cells is redundant for G-CSF-induced colony growth. This might be attributed to either alternative activation of the pathways linked to the tyrosines or to compensatory influences of other signaling pathways.

Although G-CSF-R tyrosines were not required per se for G-CSF-induced colony formation, the experiments with the addback mutants clearly suggested that the individual tyrosines exert regulatory functions. In particular, this applies to the growth inhibitory role of Tyr729 and the growth-promoting role of Tyr764. No specific inhibitory pathway had previously been assigned to Tyr729. We have identified Tyr729 here as the single tyrosine involved in SOCS3-mediated inhibition of G-CSF signaling. In similar experiments we could not functionally link SOCS1 or SOCS2 to Tyr729 (G.-J. van de G. and I.P.T., unpublished results, 2002). We hypothesize that SOCS3 binds directly to Tyr729 via its SH2 domain. Tyr729 is located in a motif (VLYGQLLGS) that shows striking homology with the SOCS3-SH2-binding sites within gp130 and the leptin receptor. Characteristics of this motif are the valine at $\mathrm{pY}-2$, a hydrophobic residue at $\mathrm{Y}+3^{43}$ and the serine at $\mathrm{Y}+6$ (or $\mathrm{Y}+5) .{ }^{42,43}$ While this paper was under review, Hörtner et al published data supporting the notion that the Tyr729-containing motif of G-CSF-R indeed forms a direct binding site for SOCS3. ${ }^{47}$ Notably, G-CSF-R deletion mutants in patients with severe congenital neutropenia that progresses to acute myeloid leukemia lack this motif, ${ }^{48-50}$ which may contribute to the hyperproliferative signaling properties of these receptor forms. ${ }^{51,52}$

The G-CSF-induced colonies grown from the $\mathrm{gcsfr}^{-/-}$bone marrow cells transduced with G-CSF-R constructs were of granulocyte, granulocyte-macrophage, macrophage, or mast cell origin and contained fully mature cells. We did not observe differences in the composition of the colonies grown from cells transduced with G-CSF-R WT, tyrosine add-back, or tyrosine null mutants. This argues against a major role of the receptor tyrosines in controlling myeloid differentiation. A similar conclusion was recently drawn by Akbarzadeh et al, ${ }^{28}$ who further demonstrated that expression of myeloperoxidase and gelatinase, enzymatic markers of granulocytic differentiation, was not affected by substitution of the tyrosines. Interestingly, these authors observed a slight, but significant, increase in the numbers of macrophage colonies and reduction of granulocyte colonies with mutant Tyr729Phe, but not with their Tyr null mutant. This suggests that Tyr729, possibly via recruitment of SOCS3, influences the balance between granulocyte and macrophage colony growth only when pathways activated via one or more of the remaining tyrosines remain intact.

Both G-CSF- and G-CSF-R-deficient mice have reduced numbers of granulocyte-macrophage colony-forming units (CFUGMs) in the bone marrow. Thus, G-CSF not only stimulates myeloid progenitors to proliferate and differentiate toward neutrophils, but also controls the size of the progenitor cell compartment in the bone marrow. The data from the sequential platings suggest that signaling pathways emanating from the G-CSF-R tyrosines contribute significantly to this control. The prominent stimulatory influence of Tyr764 suggests that activation of the p21 Ras/Erk pathway contributes to progenitor cell expansion, whereas the inhibitory signal provided by Tyr729, most likely involving SOCS3, has the opposite effect. Strikingly, Tyr704 and Tyr744, while exerting no inhibitory effect on primary colony growth, suppressed progenitor cell expansion in the replating experiments. The signaling pathways responsible for this inhibition are not known. Tyr704 and Tyr744 both function as direct docking sites for STAT3. ${ }^{25}$ STAT3 activation by G-CSF-R can also occur in the absence of receptor tyrosines. ${ }^{13,28}$ Still, we think that STAT3 activation via Tyr704 and Tyr744 may play an important role because depending on the levels of activation in conjunction with other signaling pathways, STAT3 can exert variable functions in myeloid progenitor cells. The effects of STAT3 on cell proliferation and differentiation are diverse and depend on cell type and stage of differentiation..$^{40,46,53}$ Even within one cell type, unexpected variations in the effects of STAT3, depending on the status of activation of other signaling pathways, have been reported. Based on these findings, a model was proposed in which STAT3 orchestrates conflicting signals during $\mathrm{G}_{1}$ to $\mathrm{S}$ transition in the cell cycle. ${ }^{54} \mathrm{In}$ view of this more complex role of STAT3 in the regulation of cell growth, we propose that STAT3 mediates stimulatory effects on primary colony growth and neutrophilic differentiation, thereby negatively affecting the expansion of myeloid progenitors controlled by G-CSF. Studies in which STAT3 activation in bone marrow cells can inducibly be inactivated are in progress to unravel the full spectrum of activities of STAT3 in myeloid cell development.

\section{Acknowledgments}

We thank Drs Marieke von Lindern and Joanna Prasher for their critical evaluation of this manuscript.

\section{References}

1. Demetri GD, Griffin JD. Granulocyte colonystimulating factor and its receptor [review]. Blood 1991;78:2791-2808.

2. Colotta F, Borre A, Wang JM, et al. Expression of a monocyte chemotactic cytokine by human mononuclear phagocytes. J Immunol. 1992;148: 760-765.

3. Berliner N, Hsing A, Graubert T, et al. Granulocyte colony-stimulating factor induction of norma human bone marrow progenitors results in neutrophil-specific gene expression. Blood. 1995;85 799-803.

4. Lieschke GJ. CSF-deficient mice-what have they taught us? [review]. Ciba Found Symp. 1997;204:60-74.

5. Liu F, Wu HY, Wesselschmidt R, Kornaga T, Link DC. Impaired production and increased apoptosis of neutrophils in granulocyte colony-stimulating factor receptor-deficient mice. Immunity. 1996;5: 491-501.

6. Lieschke GJ, Grail D, Hodgson G, et al. Mice lacking granulocyte colony-stimulating factor have chronic neutropenia, granulocyte and macrophage progenitor cell deficiency, and impaired neutrophil mobilization. Blood. 1994;84:17371746

7. Nicholson SE, Oates AC, Harpur AG, Ziemiecki A, Wilks AF, Layton JE. Tyrosine kinase JAK1 is associated with the granulocyte-colony-stimulating factor receptor and both become tyrosinephosphorylated after receptor activation. Proc Natl Acad Sci U S A. 1994;91:2985-2988.

8. Tian SS, Lamb P, Seidel HM, Stein RB, Rosen J. Rapid activation of the STAT3 transcription facto by granulocyte colony-stimulating factor. Blood. 1994;84:1760-1764.

9. Tian SS, Tapley P, Sincich C, Stein RB, Rosen J, Lamb P. Multiple signaling pathways induced by granulocyte colony-stimulating factor involving activation of JAKs, STAT5, and/or STAT3 are required for regulation of three distinct classes of immediate early genes. Blood. 1996;88:44354444.

10. de Koning JP, Dong F, Smith L, et al. The membrane-distal cytoplasmic region of human granulocyte colony-stimulating factor receptor is required for STAT3 but not STAT1 homodimer formation. Blood. 1996;87:1335-1342.

11. Shimoda K, Iwasaki H, Okamura S, et al. G-CSF induces tyrosine phosphorylation of the JAK2 protein in the human myeloid G-CSF responsive and proliferative cells, but not in mature neutrophils. Biochem Biophys Res Commun. 1994;203: 922-928.

12. Shimoda K, Feng J, Murakami H, et al. Jak1 plays an essential role for receptor phosphorylation and Stat activation in response to granulocyte colony-stimulating factor. Blood. 1997;90: 597-604.

13. Ward AC, Hermans MH, Smith L, et al. Tyrosinedependent and -independent mechanisms of STAT3 activation by the human granulocyte 
colony-stimulating factor (G-CSF) receptor are differentially utilized depending on G-CSF concentration. Blood. 1999;93:113-124.

14. Corey SJ, Burkhardt AL, Bolen JB, Geahlen RL, Tkatch LS, Tweardy DJ. Granulocyte colonystimulating factor receptor signaling involves the formation of a three-component complex with Lyn and Syk protein-tyrosine kinases. Proc Natl Acad Sci U S A. 1994;91:4683-4687.

15. Corey SJ, Dombrosky-Ferlan PM, Zuo S, et al Requirement of Src kinase Lyn for induction of DNA synthesis by granulocyte colony-stimulating factor. J Biol Chem. 1998;273:3230-3235.

16. Ward AC, Monkhouse JL, Csar XF, Touw IP, Bello PA. The Src-like tyrosine kinase Hck is activated by granulocyte colony-stimulating factor (G-CSF) and docks to the activated G-CSF receptor. Biochem Biophys Res Comm. 1998;251:117-123.

17. Bashey A, Healy L, Marshall CJ. Proliferative but not nonproliferative responses to granulocyte colony-stimulating factor are associated with rapid activation of the p21ras/MAP kinase signaling pathway. Blood. 1994;83:949-957.

18. Nicholson SE, Novak U, Ziegler SF, Layton JE. Distinct regions of the granulocyte colony-stimulating factor receptor are required for tyrosine phosphorylation of the signaling molecules JAK2 Stat3, and p42, p44MAPK. Blood. 1995;86:36983704 .

19. Ward AC, Monkhouse JL, Hamilton JA, Csar XF Direct binding of Shc, Grb2, SHP-2 and p40 to the murine granulocyte colony-stimulating factor receptor. Biochim Biophys Acta. 1998;1448:7076.

20. Tapley P, Shevde NK, Schweitzer PA, et al. Increased G-CSF responsiveness of bone marrow cells from hematopoietic cell phosphatase deficient viable motheaten mice. Exp Hematol. 1997; 25:122-131.

21. de Koning JP, Schelen AM, Dong F, et al. Specific involvement of tyrosine 764 of human granulocyte colony-stimulating factor receptor in signal transduction mediated by $\mathrm{p} 145 / \mathrm{Shc} / \mathrm{GRB} 2$ or p90/GRB2 complexes. Blood. 1996;87:132-140.

22. Dong F, van Buitenen $C$, Pouwels K, Hoefsloot LH, Löwenberg B, Touw IP. Distinct cytoplasmic regions of the human granulocyte colony-stimulating factor receptor involved in induction of proliferation and maturation. Mol Cell Biol. 1993;13: 7774-7781.

23. Fukunaga R, Ishizaka-Ikeda E, Pan CX, Seto Y, Nagata S. Functional domains of the granulocyte colony-stimulating factor receptor. EMBO J. 1991;10:2855-2865

24. de Koning JP, Soede-Bobok AA, Schelen AM, et al. Proliferation signaling and activation of Shc p21Ras, and Myc via tyrosine 764 of human granulocyte colony-stimulating factor receptor. Blood. 1998;91:1924-1933.

25. Ward AC, Smith L, de Koning JP, van Aesch Y, Touw IP. Multiple signals mediate proliferation, differentiation, and survival from the granulocyte colony-stimulating factor receptor in myeloid 32D cells. J Biol Chem. 1999;274:14956-14962.

26. de Koning JP, Touw IP. Advances in understanding the biology and function of the G-CSF receptor [review]. Curr Opin Hematol. 1996;3:180-184.
27. Dong F, Liu X, de Koning JP, et al. Stimulation of Stat5 by granulocyte colony-stimulating factor (G-CSF) is modulated by two distinct cytoplasmic regions of the G-CSF receptor. J Immunol. 1998; 161:6503-6509.

28. Akbarzadeh S, Ward AC, McPhee DO, Alexande WS, Lieschke GJ, Layton JE. Tyrosine residues of the granulocyte colony-stimulating factor receptor transmit proliferation and differentiation signals in murine bone marrow cells. Blood. 2002; 99:879-887.

29. Rausch O, Marshall CJ. Cooperation of p38 and extracellular signal-regulated kinase mitogenactivated protein kinase pathways during granulocyte colony-stimulating factor-induced hemopoietic cell proliferation. J Biol Chem. 1999;274: 4096-4105

30. Ward AC, Oomen SP, Smith L, et al. The SH2 domain-containing protein tyrosine phosphatase SHP-1 is induced by granulocyte colony-stimulating factor (G-CSF) and modulates signaling from the G-CSF receptor. Leukemia. 2000;14:1284 1291

31. Dong F, Qiu Y, Yi T, Touw IP, Larner AC. The carboxyl terminus of the granulocyte colony-stimulating factor receptor, truncated in patients with severe congenital neutropenia/acute myeloid leukemia, is required for $\mathrm{SH} 2$-containing phosphatase-1 suppression of Stat activation. J Immunol. 2001;167:6447-6452.

32. Krebs DL, Hilton DJ. SOCS proteins: negative regulators of cytokine signaling. Stem Cells. 2001;19:378-387.

33. Kile BT, Alexander WS. The suppressors of cytokine signalling (SOCS). Cell Mol Life Sci. 2001; 58:1627-1635.

34. Yasukawa H, Sasaki A, Yoshimura A. Negative regulation of cytokine signaling pathways. Annu Rev Immunol. 2000;18:143-164.

35. Yasukawa $\mathrm{H}$, Misawa $\mathrm{H}$, Sakamoto $\mathrm{H}$, et al. The JAK-binding protein JAB inhibits Janus tyrosine kinase activity through binding in the activation loop. EMBO J. 1999;18:1309-1320.

36. Smith AG, Hooper ML. Buffalo rat liver cells produce a diffusible activity which inhibits the differentiation of murine embryonal carcinoma and embryonic stem cells. Dev Biol. 1987;121:1-9.

37. Sambrook J, Fritsch EF, Maniatis T. Molecular Cloning: A Laboratory Manual. Cold Spring Harbor, NY. Cold Spring Harbor Laboratory: 1989.

38. Hermans MH, Ward AC, Antonissen C, Karis A, Löwenberg B, Touw IP. Perturbed granulopoiesis in mice with a targeted mutation in the granulocyte colony-stimulating factor receptor gene associated with severe chronic neutropenia. Blood. 1998:92:32-39.

39. Cowland JB, Borregaard N. Molecular character ization and pattern of tissue expression of the gene for neutrophil gelatinase-associated lipocalin from humans. Genomics. 1997;45:17-23.

40. de Koning JP, Soede-Bobok AA, Ward AC, et al STAT3-mediated differentiation and survival and of myeloid cells in response to granulocyte colony-stimulating factor: role for the cyclindependent kinase inhibitor p27(Kip1). Oncogene. 2000;19:3290-3298

41. Hall CV, Jacob PE, Ringold GM, Lee F. Expres- sion and regulation of Escherichia coli lacZ gene fusions in mammalian cells. J Mol Appl Genet. 1983;2:101-109.

42. Eyckerman S, Broekaert D, Verhee A, Vandekerckhove J, Tavernier J. Identification of the Y985 and Y1077 motifs as SOCS3 recruitment sites in the murine leptin receptor. FEBS Lett. 2000;486: 33-37.

43. Nicholson SE, De Souza D, Fabri LJ, et al. Suppressor of cytokine signaling-3 preferentially binds to the SHP-2-binding site on the shared cytokine receptor subunit gp130. Proc Natl Acad Sci U S A. 2000;97:6493-6498.

44. Chakraborty A, Dyer KF, Cascio M, Mietzner TA Tweardy DJ. Identification of a novel Stat3 recruitment and activation motif within the granulocyte colony-stimulating factor receptor. Blood. 1999:93:15-24.

45. Shimozaki K, Nakajima K, Hirano T, Nagata S Involvement of STAT3 in the granulocyte colonystimulating factor-induced differentiation of myeloid cells. J Biol Chem. 1997;272:25184-25189.

46. McLemore ML, Grewal S, Liu F, et al. STAT-3 activation is required for normal G-CSF-dependent proliferation and granulocytic differentiation. Immunity. 2001;14:193-204.

47. Hörtner M, Nielsch U, Mayr LM, Johnston JA, Heinrich PC, Haan S. Suppressor of cytokine signaling-3 is recruited to the activated granulocytecolony stimulating factor receptor and modulates its signal transduction. J Immunol. 2002;169: 1219-1227.

48. Dong F, Dale DC, Bonilla MA, et al. Mutations in the granulocyte colony-stimulating factor receptor gene in patients with severe congenital neutropenia. Leukemia. 1997:11:120-125.

49. Dong F, Brynes RK, Tidow N, Welte K, Löwenberg B, Touw IP. Mutations in the gene for the granulocyte colony-stimulating-factor receptor in patients with acute myeloid leukemia preceded by severe congenital neutropenia [see comments]. N Engl J Med. 1995;333:487-493.

50. Tidow N, Pilz C, Kasper B, Welte K. Frequency of point mutations in the gene for the G-CSF receptor in patients with chronic neutropenia undergoing G-CSF therapy. Stem Cells. 1997;1:113-119.

51. McLemore ML, Poursine-Laurent J, Link DC. Increased granulocyte colony-stimulating factor responsiveness but normal resting granulopoiesis in mice carrying a targeted granulocyte colonystimulating factor receptor mutation derived from a patient with severe congenital neutropenia. J Clin Invest. 1998;102:483-492.

52. Hermans MH, Antonissen C, Ward AC, Mayen AE, Ploemacher RE, Touw IP. Sustained receptor activation and hyperproliferation in response to granulocyte colony-stimulating factor (G-CSF) in mice with a severe congenital neutropenia/acute myeloid leukemia-derived mutation in the G-CSF receptor gene. J Exp Med. 1999;189:683-692.

53. Niwa H, Burdon T, Chambers I, Smith A. Selfrenewal of pluripotent embryonic stem cells is mediated via activation of STAT3. Genes Dev. 1998;12:2048-2060.

54. Fukada T, Ohtani T, Yoshida Y, et al. STAT3 orchestrates contradictory signals in cytokineinduced $\mathrm{G}_{1}$ to $\mathrm{S}$ cell-cycle transition. EMBO J. 1998:17:6670-6677. 